\title{
Biocontrole da mancha-angular do feijoeiro por antagonistas bacterianos
}

\author{
Flávio Augusto de Oliveira Garcia( ${ }^{(1)}$ e Reginaldo da Silva Romeiro(2)
}

(1)Universidade Estadual do Centro-Oeste, Departamento de Engenharia Florestal, PR 153, Km 7, CEP $84500-000$ Irati, PR.
E-mail: msfa_garcia@yahoo.com.br ${ }^{(2)} / n$ memoriam

\begin{abstract}
Resumo-O objetivo deste trabalho foi avaliar o efeito de isolados de Bacillus cereus e Pseudomonas putida sobre a severidade da mancha-angular do feijoeiro, em condições de campo. Quatro experimentos foram conduzidos em épocas favoráveis à mancha-angular (Pseudocercospora griseola), com as cultivares Pérola e Ouro Negro. Os experimentos foram realizados em delineamento de blocos ao acaso, com seis repetições. Os tratamentos foram pulverizações sobre as plantas com três estirpes de B. cereus (UFV-172, UFV-101 e UFV-75) e duas estirpes de $P$. putida (UFV-53 e UFV-Pp), acibenzolar-S-metil, fungicida clorotalonil e controle pulverizado com água, no total de oito tratamentos. Os tratamentos foram aplicados por atomização no filoplano de plantas de feijoeiro, semanalmente, a partir do $15^{\circ}$ dia após a emergência até o fim do ensaio. Calculou-se a área abaixo da curva de progresso da mancha-angular do feijoeiro; a doença ocorreu naturalmente. A produção foi avaliada pela massa média de sementes por planta. Os antagonistas foram eficientes em reduzir a severidade da doença, em comparação à testemunha, e obtiveram o mesmo nível de controle do tratamento químico. O menor índice de severidade da doença propiciou melhor produção do que o tratamento controle.
\end{abstract}

Termos para indexação: Bacillus cereus, Phaseolus vulgaris, Pseudocercospora griseola, Pseudomonas putida.

\section{Biocontrol of bean angular leaf spot by bacterial antagonists}

\begin{abstract}
The objective of this work was to evaluate the effect of Bacillus cereus and Pseudomonas putida isolates on the severity of the angular leaf spot of common bean under field conditions. Four trials were carried out in favorable seasons to angular leaf spot (Pseudocercospora griseola), using the cultivars Pérola and Ouro Negro. The assays were assembled in a randomized block design with six replicates. The treatments were plant-sprayings with three strains of $B$. cereus (UFV-172, UFV-101 and UFV-75) and two strains of $P$. putida (UFV-53 and UFV-Pp), acibenzolar-S-methyl, chlorothalonil fungicide and the control with water, in a total of eight treatments. The treatments were applied weekly by spraying the phylloplane of bean plants, starting from the $15^{\text {th }}$ day after seedling emergency until the end of the assay. The area under the disease progress curve of the angular leaf spot was calculated; the disease occurred naturally. Yield was evaluated by the average seed mass per plant. The antagonists were effective in reducing the severity of the disease, in comparison to the control, and they had the same control level as the chemical treatment. The lowest index of the disease severity provided the best yield, in comparison to the control treatment.
\end{abstract}

Index terms: Bacillus cereus, Phaseolus vulgaris, Pseudocercospora griseola, Pseudomonas putida.

\section{Introdução}

A mancha-angular, causada por Pseudocercospora griseola (Sacc.) Crous e Braun, é uma das principais doenças que ocorre na cultura do feijão(Reis-Prado etal., 2006), se não a mais importante para algumas regiões do Brasil. Segundo Paula Júnior \& Zambolim (2006), as perdas causadas pela ocorrência da mancha-angular são importantes fatores que determinam a baixa produtividade da cultura no Brasil.

De acordo com Reis-Prado et al. (2006), os controles cultural e químico da doença não apresentam níveis desejáveis de manejo, além disso há riscos ambientais pelo uso de fungicidas. A resistência genética é dificultada pela alta variabilidade do patógeno (Ragagnin et al., 2003; Sartorato \& Rava, 2003; Faleiro et al., 2004; Reis-Prado et al., 2006; Melo et al., 2008; Silva et al., 2009). Uma possível alternativa para o manejo da doença seria o uso do controle biológico. Esse método reduz os riscos de dano ambiental e tem demonstrado resultados promissores para o controle da mancha-angular do feijoeiro (Viecelli et al., 2009, 2010).

Entre os organismos utilizados como agentes de controle biológico de plantas, as espécies bacterianas têm sido relatadas como antagonistas promissores (Romeiro, 2007a). Normalmente, a estratégia mais utilizada é a dispensação dessas bactérias junto ao

Pesq. agropec. bras., Brasília, v.46, n.12, p.1603-1608, dez. 2011 
sistema radicular das plantas (Bashan, 1998). Alguns trabalhos vêm apresentando resultados positivos com a aplicação dessas bactérias à superfície das folhas. Carrer Filho et al. (2008) observaram que a estirpe SON17 de Nocardioides thermolilacinus foi capaz de controlar o progresso da pinta-preta do tomateiro, quando aplicada semanalmente sobre a superfície das folhas. Uma estirpe de Bacillus cereus, pulverizada na superfície foliar de tomateiro, foi capaz de reduzir a severidade da mancha-bacteriana pequena, causada por Pseudomonas syringae pv. tomato (Halfeld-Vieira et al., 2006). Em um estudo sobre uma estirpe de B. cereus e uma de Pseudomonas putida, pulverizadas na parte aérea de feijoeiro, observou-se que os dois antagonistas foram capazes de reduzir o progresso da ferrugem (Uromyces appendiculatus) (Vieira Júnior, 2005). Outros trabalhos relatam o controle biológico da ferrugem do feijoeiro (Mizubuti et al.,1995; Yuen et al., 2001). Porém, há poucos relatos sobre o uso de bactérias como agentes de controle biológico da mancha-angular do feijoeiro.

O objetivo deste trabalho foi avaliar o efeito de isolados de Bacillus cereus e Pseudomonas putida sobre a severidade da mancha-angular do feijoeiro, em condições de campo.

\section{Material e Métodos}

Avaliaram-se três estirpes de $B$. cereus, a UFV-172 e a UFV-75, isoladas de filoplano de feijoeiro, e a UFV-101, isolada de rizosfera de tomateiro (Silva et al., 2003), além de duas estirpes de $P$. putida, a UFV-Pp isolada de filoplano de tomateiro (Halfeld-Vieira et al., 2006), e a UFV-53, isolada de rizosfera de feijoeiro. Os microrganismos utilizados pertencem à coleção do Laboratório de Bacteriologia de Plantas e Controle Biológico da Universidade Federal de Viçosa. Todos os isolados foram cultivados no meio 523 (Kado \& Heskett, 1970) e, posteriormente, preservados por repicagem tubo-a-tubo em óleo mineral (Romeiro, 2007b).

Realizaram-se experimentos de fevereiro a junho de 2008 (experimentos 1 e 2) e de março a julho de 2008 (experimentos 3 e 4), em época do ano favorável ao surgimento de mancha-angular, em que a precipitação média mensal do período foi de $71,2 \mathrm{~mm}$, a temperatura máxima de $28^{\circ} \mathrm{C}$ (fevereiro), a mínima de $9,6^{\circ} \mathrm{C}$ (julho) e a média do período foi de $20,7^{\circ} \mathrm{C}$. Utilizou-se a área experimental do Departamento de Fitopatologia, da Universidade Federal de Viçosa, em Viçosa, $\mathrm{MG}$, a $20^{\circ} 75^{\prime} \mathrm{S}, 42^{\circ} 85^{\prime} \mathrm{W}$, com clima Cwa segundo classificação de Köppen. O solo é do tipo Latossolo Vermelho-Amarelo (Santos et al., 2006).

Os experimentos foram conduzidos em delineamento de blocos ao acaso, com seis blocos, com os tratamentos: UFV-172, UFV-101, UFV-75, UFV-53, UFV-Pp, acibenzolar-S-metil (ASM) e o fungicida clorotalonil. Como tratamento controle, utilizou-se água. Nos experimentos 1 e 3, foi utilizado a cultivar Pérola, e nos experimentos 2 e 4, a Ouro Negro.

Procedeu-se à semeadura em sulcos, com densidade de plantio de 14 sementes por metro, e espaçamento entre sulcos de $60 \mathrm{~cm}$; a adubação, com $250 \mathrm{~kg} \mathrm{ha}^{-1} \mathrm{de}$ N-P-K (4-14-8), foi aplicada a lanço, antes do plantio, na área total. A área de cada ensaio foi de 0,5 ha com parcela útil de cerca de $100 \mathrm{~m}^{2}$. Utilizaram-se plantas no estádio V3 de desenvolvimento, conforme Santos \& Gavilanes (2006), em que o filoplano foi atomizado com suspensão de propágulos das cinco bactérias $\left(10^{8} \mathrm{UFC} \mathrm{mL}^{-1}\right)$. As suspensões foram obtidas por meio de cultivo das bactérias, em placas de Petri com meio 523 , por 24 horas a $28^{\circ} \mathrm{C}$, suspensas pela lavagem da superfície do meio comágua de torneira. A concentração da suspensão foi ajustada em espectrofotômetro, de forma a se obterem $10^{8} \mathrm{UFC} \mathrm{mL}^{-1}$ para cada isolado. Os outros tratamentos consistiram da pulverização de uma suspensão de ASM (150 $\left.\mathrm{mg} \mathrm{mL}^{-1}\right)$, fungicida clorotalonil ( $2 \mathrm{mg} \mathrm{mL}^{-1}$ de i.a.) e água. Os tratamentos foramaplicados semanalmenteatéo fim do experimento, que se deu no estádio R9, em junho e julho de 2008.

Foi avaliada a severidade da mancha-angular, que ocorreu naturalmente, pela escala diagramática proposta por Godoy et al. (1997), composta por nove níveis de severidade. Nos dois ensaios conduzidos de fevereiro a junho, foram feitas 15 avaliações, de 4 de março a 24 de junho de 2008 e, nos dois experimentos realizados de março a julho, realizaramse nove avaliações, de 8 de abril a 22 de julho de 2008 . Calculou-se a área abaixo da curva de progresso de doença (AACPD), e os resultados foram analisados pela análise de variância, e as médias foram comparadas pelo teste de Tukey, a 5\% de probabilidade. Os dados foram analisados com o programa SAEG (2005).

A produção foi avaliada pela massa média de sementes por plantas. Para isto, as sementes foram debulhadas e pesadas. Posteriormente, foram colocadas 
em uma estufa de circulação de ar a $50^{\circ} \mathrm{C}$ por cinco dias, até se obter massa constante e, em seguida, foram pesadas novamente. Para cada tratamento, dividiu-se a massa de sementes secas pelo número de plantas de cada tratamento, tendo-se obtido a massa média de sementes secas por planta. Os dados foram analisados por meio de análise de variância, e as médias foram comparadas pelo teste de Tukey, a 5\% de probabilidade, pelo programa SAEG (2005).

\section{Resultados e Discussão}

Nos experimentos realizados de fevereiro a junho de 2008 (experimentos 1 e 2), a incidência de mancha-angular teve início aproximadamente aos 48 dias após a semeadura, no estádio V3 das plantas. Observouse também as ocorrências de antracnose (Colletotrichum lindemuthianum), cercosporiose (Cercospora canescens) e mancha-de-alternária (Alternaria sp.) nas duas cultivares testadas, porém, não caracterizadas como epidemias, pois ocorreram em pontos isolados dentro dos blocos.

A área abaixo da curva de progresso da doença da mancha-angular do feijoeiro foi reduzida em todos os tratamentos, em comparação ao tratamento controle, no ensaio com a cultivar Pérola (Figura $1 \mathrm{~A}$ ). A aplicação do fungicida clorotalonil foi responsável pela menor severidade da doença. Entre os antagonistas testados, as estirpes UFV-53, UFV-75 e UFV-172 foram as que apresentaram maior efeito sobre a redução da severidade da doença.

No ensaio com a cultivar Ouro Negro, todos os tratamentos diferiram significativamente do tratamento controle (Figura $1 \mathrm{~B}$ ).

Nos experimentos conduzidos de março a julho de 2008 (experimentos 3 e 4), a incidência de mancha-angular teve início aproximadamente aos 57 dias após a semeadura. Observou-se também a ocorrência de ferrugem (Uromyces appendiculatus) cerca de 45 dias após a emergência das plantas.
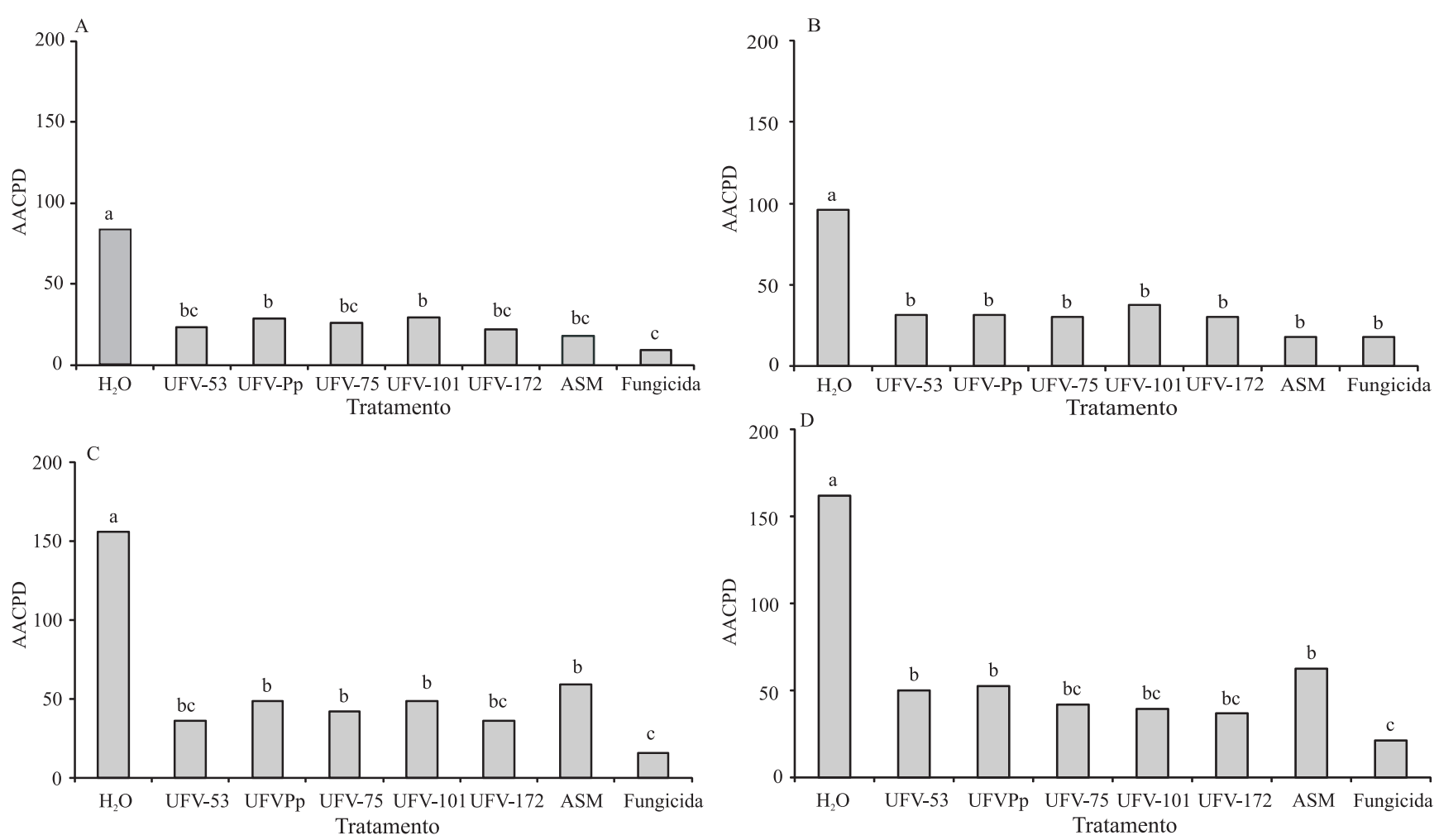

Figura 1. Área abaixo da curva de progresso da doença (AACPD), da mancha-angular do feijoeiro, após aplicação dos tratamentos: estirpes de Bacillus cereus (UFV-172, UFV-101, UFV-75) e de Pseudomonas putida (UFV-53 e UFV-Pp), em suspensões com $10^{8} \mathrm{UFC} \mathrm{mL}^{-1}$; fungicida clorotalonil ( $2 \mathrm{mg} \mathrm{mL}^{-1}$ ); acibenzolar-S-metil (ASM, $150 \mathrm{mg} \mathrm{mL}^{-1}$ ); e tratamento controle com água. A, cultivar Pérola, e B, cultivar Ouro Negro, de fevereiro a junho de 2008. C, 'Pérola', e D, 'Ouro Negro', de março a julho de 2008. Médias seguidas de letras iguais não diferem, entre si, pelo teste Tukey, a 5\% de probabilidade. 
No ensaio com a cultivar Pérola, todos os tratamentos, em comparação ao tratamento controle, foram eficientes em reduzir a severidade da mancha-angular (Figura 1 C). Os tratamentos UFV-101, UFV-75, UFV-Pp e ASM foram significativamente inferiores ao de controle químico, e os tratamentos UFV-172 e UFV-53 foram significativamente iguais ao do fungicida clorotalonil. No tratamento com a cultivar Ouro Negro também se observou redução da severidade da doença pelos tratamentos, em relação ao tratamento controle (Figura 1 D). Os tratamentos compostos pelas estirpes de $P$. putida e ASM foram inferiores ao de clorotalonil.

Viecelli et al. $(2009,2010)$ obtiveram resultados semelhantes, com a redução da severidade da mancha-angular do feijoeiro, em condições de campo, quando a superfície foliar das plantas foi aspergida com filtrados do fungo Pycnoporus sanguineus. Em um experimento com extrato aquoso de basidiocarpos de $P$. sanguineus, observou-se a redução da severidade de antracnose em feijoeiro, quando a superfície foliar das plantas foi aspergida com esse preparado (Assi, 2005). Embora esses trabalhos relatem o biocontrole de doenças do feijoeiro, inclusive a mancha-angular, todos utilizam culturas fúngicas ou metabólitos fúngicos.

Os resultados do presente trabalho relatam o controle biológico da mancha-angular do feijoeiro pelo uso de isolados bacterianos, e apresenta uma nova possibilidade para o manejo integrado da doença.

$\mathrm{O}$ indutor de resistência ASM proporcionou controle da doença. Embora Soares et al. (2004) contestem sua eficácia no controle de doenças da cultura do feijoeiro, no presente trabalho observouse que o produto foi capaz de reduzir a severidade da doença em relação ao tratamento controle (Figura 1).

Todas as plantastratadas com as estirpes de B. cereus e P. putida tiveram maior massa de sementes por planta do que o tratamento controle, à exceção do experimento 3 , em que os isolados UFV-53 e UFV-Pp não diferiram significativamente do tratamento controle (Tabela 1).

Nos experimentos 2, 3 e 4, as plantas tratadas com a estirpe UFV-172 tiveram produção superior às plantas do tratamento com o fungicida clorotalonil. Corrêa et al. (2011) trabalharam com pepino e observaram
Tabela 1. Massa de sementes por planta (g) das cultivares de feijoeiro, após a aplicação dos tratamentos ${ }^{(1)}$.

\begin{tabular}{lcccc}
\hline Tratamento $^{(2)}$ & \multicolumn{2}{c}{ 'Pérola' } & \multicolumn{2}{c}{ 'Ouro Negro' } \\
\cline { 2 - 5 } & Experimento 1 & Experimento 3 & Experimento 2 & Experimento 4 \\
\hline H2O & $34,0 \mathrm{c}$ & $25,3 \mathrm{C}$ & $19,6 \mathrm{c}$ & $19,5 \mathrm{C}$ \\
UFV-53 & $79,1 \mathrm{ab}$ & $31,7 \mathrm{BC}$ & $44,9 \mathrm{ab}$ & $36,2 \mathrm{AB}$ \\
UFV-Pp & $76,2 \mathrm{ab}$ & $30,3 \mathrm{C}$ & $45,3 \mathrm{ab}$ & $33,4 \mathrm{~B}$ \\
UFV-75 & $82,8 \mathrm{ab}$ & $43,2 \mathrm{AB}$ & $43,7 \mathrm{ab}$ & $33,7 \mathrm{~B}$ \\
UFV-101 & $84,6 \mathrm{ab}$ & $43,8 \mathrm{~A}$ & $44,0 \mathrm{ab}$ & $41,1 \mathrm{AB}$ \\
UFV-172 & $90,0 \mathrm{a}$ & $44,6 \mathrm{~A}$ & $57,0 \mathrm{a}$ & $43,6 \mathrm{~A}$ \\
ASM & $57,5 \mathrm{bc}$ & $28,3 \mathrm{C}$ & $43,0 \mathrm{ab}$ & $19,6 \mathrm{C}$ \\
Fungicida & $79,5 \mathrm{ab}$ & $35,3 \mathrm{BC}$ & $37,5 \mathrm{~b}$ & $34,3 \mathrm{~B}$ \\
\hline CV(\%) & 21,34 & 31,66 & 20,99 & 23,17 \\
\hline
\end{tabular}

${ }^{(1)}$ Médias seguidas de letras iguais, nas colunas, não diferem pelo teste de Tukey, a 5\% de probabilidade. ${ }^{(2)}$ Estirpes de Bacillus cereus (UFV-172, UFV-101, UFV-75) e de Pseudomonas putida (UFV-53 e UFV-Pp), em

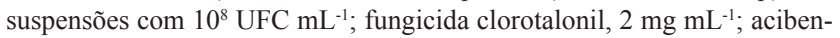
zolar-s-metil (ASM), $150 \mathrm{mg} \mathrm{mL}^{-1}$; e tratamento controle com água. Experimentos 1 e 2, realizados de fevereiro a junho de 2008. Experimentos 3 e 4, realizados de março a julho de 2008.

que isolados bacterianos de Gordonia rubripertincta e Pseudomonas stutzeri foram capazes de atuar no biocontrole da podridão- radicular, causada por Pythium aphanidermatum e, concomitantemente, promoverem o crescimento de mudas, o que poderia explicar a maior produção com a aplicação dos microrganismos do que com a aplicação do fungicida.

Em relação ao tratamento com ASM, a produção das plantas tratadas com o produto não diferiu significativamente do tratamento controle, exceto no experimento 2. A menor produção das plantas nesse tratamento poderia ser explicada pelo modo como esse produto promove o controle. O ASM é um eliciador químico de resistência da planta, segundo Kuhn \& Pascholati (2007) quando os mecanismos de defesa da planta são ativados, há um custo energético para ela, que compromete algumas de suas funções como a reprodução.

\section{Conclusões}

1. As três estirpes de Bacillus cereus e as duas de Pseudomonas putida são eficazes em reduzir a ocorrência da mancha-angular, quando pulverizadas no filoplano de plantas de feijoeiro.

2. O indutor de resistência acibenzolar-S-metil (ASM) é eficaz no controle da mancha-angular. 


\section{Agradecimentos}

À Coordenação de Aperfeiçoamento de Pessoal de Nível Superior, pelo financiamento da pesquisa; ao Conselho Nacional de Desenvolvimento Científico e Tecnológico, por bolsa concedida; e ao Professor José Eustáquio de Souza Carneiro, da Universidade Federal de Viçosa, pela cessão das sementes utilizadas na execução dos experimentos.

\section{Referências}

ASSI, L. Controle de Colletotrichum lindemuthianum (Sacc. et Magn.) Scrib., na cultura do feijão (Phaseolus vulgaris L.) pelo extrato do cogumelo Pycnoporus sanguineus (L. ex. Fr.). 2005. 51p. Dissertação (Mestrado) - Universidade Estadual do Oeste do Paraná, Marechal Cândido Rondon.

BASHAN, Y. Inoculants of plant growth-promoting bacteria for use in agriculture. Biotechnology Advances, v.16, p.729-770, 1998.

CARRER FILHO, R.; ROMEIRO, R.S.; GARCIA, F.A.O. Biocontrole de doenças de parte aérea do tomateiro por Nocardioides thermolilacinus. Tropical Plant Pathology, v.33, p.457-460, 2008.

CORRÊA, E.B.; GALVÃO, J.A.H.; BETTIOL, W. Controle biológico da podridão radicular e promoção de crescimento em pepino hidropônico com microrganismos de manguezais. Pesquisa Agropecuária Brasileira, v.46, p.130-136, 2011.

FALEIRO, F.G.; RAGAGNIN, V.A.; MOREIRA, M.A.; BARROS, E.G. Use of molecular markers to accelerate the breeding of common bean lines resistant to rust and anthracnose. Euphytica, v.138, p.213-218, 2004.

GODOY, C.V.; CARNEIRO, S.M.T.P.G.; IAMAUTI, M.T.; PRIA, M.D.; AMORIM, L.; BERGER, R.D.; BERGAMIN FILHO, A. Diagramatic scale for bean diseases: development and validation. Journal of Plant Diseases and Protection, v.104, p.336-345, 1997.

HALFELD-VIEIRA, B.A.; VIEIRA JÚNIOR, J.R.; ROMEIRO, R. da S.; SILVA, H.S.A.; BARACAT-PEREIRA, M.C. Induction of systemic resistance in tomato by the autochthonous phylloplane resident Bacillus cereus. Pesquisa Agropecuária Brasileira, v.41, p.1247-1252, 2006.

KADO, C.I.; HESKETT, M.G. Selective media for isolation of Agrobacterium, Corynebacterium, Erwinia, Pseudomonas and Xanthomonas. Phytopathology, v.60, p.969-979, 1970.

KUHN, O.J.; PASCHOLATI, S.F. Custo adaptativo da resistência induzida no controle de fitopatógenos. In: RODRIGUES, F.A.; ROMEIRO, R.S. Indução de resistência em plantas a patógenos. Visconde do Rio Branco: Suprema Gráfica, 2007. p.67-91.

MELO, C.L.P. de; RAGAGNIN, V.A.; ARRUDA, K.M.A.; BARROS, E.G.; CARNEIRO, P.C.S.; PAULA JÚNIOR, T.J. de; MOREIRA, M.A.; CARNEIRO, J.E. de S. Caracterização fenotípica e molecular de genitores de feijão tipo carioca quanto à resistência a patógenos. Pesquisa Agropecuária Brasileira, v.43, p.495-504, 2008.

MIZUBUTI, E.S.G.; MAFFIA, L.A.; MUCHOVEI, J.J.; ROMEIRO, R.S.; BATISTA, U.G. Epidemiological aspects of Uromyces appendiculatus on dry bean (Phaseolus vulgaris) after treatment with Bacillus subtilis. Journal of Phytopathology, v.143, p.689-691, 1995.

PAULA JÚNIOR, T.J.; ZAMBOLIM, L. Doenças. In: VIEIRA, C.; PAULA JÚNIOR, T.J.; BORÉM, A. (Ed.). Feijão. 2.ed. Viçosa: UFV, 2006. p.359-414.

RAGAGNIN, V.A.; ALZATE-MARIN, A.L.; SOUZA, T.L.P.O.; ARRUDA, K.M.A.; MOREIRA, M.A.; BARROS, E.G. Avaliação da resistência de isolinhas de feijoeiro a diferentes patótipos de Colletotrichum lindemuthianum, Uromyces appendiculatus e Phaeoisariopsis griseola. Fitopatologia Brasileira, v.28, p.591-596, 2003.

REIS-PRADO, F.G.; SARTORATO, A.; COSTA, J.G.C.; RAVA, C.A.; SIBOV, S.T.; PINHEIRO, J.B.; CARNEIRO, M. S. Reação de cultivares de feijoeiro comum à mancha angular em casa de vegetação. Fitopatologia Brasileira, v.31, p.306-309, 2006.

ROMEIRO, R.S. Controle biológico de doenças de plantas: fundamentos. Viçosa: UFV, 2007a. 269p.

ROMEIRO, R.S. Controle biológico de doenças de plantas: procedimentos. Viçosa: UFV, 2007b. 172p.

SAEG. Sistema para Análise Estatística e Genética. Versão 9.0. Viçosa: Fundação Arthur Bernardes, 2005.

SANTOS, H.G. dos; JACOMINE, P.K.T.; ANJOS, L.H.C. dos; OLIVEIRA, V.A. de; OLIVEIRA, J.B. de; COELHO, M.R.; LUMBRERAS, J.F.; CUNHA, T.J.F. (Ed.). Sistema brasileiro de classificação de solos. 2.ed. Rio de Janeiro: Embrapa Solos, 2006. $306 \mathrm{p}$.

SANTOS, J.B.; GAVILANES, M.L. Botânica. IN: VIEIRA, C.; PAULA JÚNIOR, T.J.; BORÉM, A. (Ed.). Feijão. 2.ed. Viçosa: UFV, 2006. p.41-66.

SARTORATO, A.; RAVA, C.A. Controle químico da mancha angular do feijoeiro comum. Summa Phytopathologica, v.29, p.202-204, 2003.

SILVA, D.V.F. e; SANTOS, J.B. dos; ABREU, Â. de F.B.; PARRELLA, R.A. da C. Seleção de linhagens de feijão rosinha de boa cocção, resistentes à antracnose e mancha angular. Bragantia, v.68, p.583-591, 2009.

SILVA, H.S.A.; ROMEIRO, R.S.; MOUNTEER, A. Development of a root colonization bioassay for rapid screening of rhizobacteria for potential biocontrol agents. Journal of Phytopathology, v.151, p.42-46, 2003.

SOARES, R.M.; MARINGONI, A.C.; LIMA, G.P.P. Ineficiência de acibenzolar-S-methyl na indução de resistência de feijoeiro à murcha-de-Curtobacterium. Fitopatologia Brasileira, v.29, p.373-377, 2004.

VIECELLI, C.A.; STANGARLIN, J.R.; KUHN, O.J.; SCHWAN-ESTRADA, K.R.F. Indução de resistência em feijoeiro à mancha angular por extratos de micélio de Pycnoporus sanguineus. Summa Phytopathologica, v.36, p.73-80, 2010.

VIECELLI, C.A.; STANGARLIN, J.R.; KUHN, O.J.; SCHWAN-ESTRADA, K.R.F. Indução de resistência em 
feijoeiro por filtrado de cultura de Pycnoporus sanguineus contra Pseudocercospora griseola. Tropical Plant Pathology, v.34, p.087-096, 2009.

VIEIRA JÚNIOR, J.R. Procariotas residentes de filoplano do feijoeiro como agentes de biocontrole de enfermidades da parte aérea da cultura. 2005. 146p. Tese (Doutorado) - Universidade Federal de Viçosa, Viçosa.

YUEN, G.Y.; STEADMAN, J.R.; LINDGREN, D.T.; SCHA, D.; JOCHUM, C. Bean rust biological control using bacterial agents. Crop Protection, v.20, p.395-402, 2001.

Recebido em 24 de junho de 2011 e aprovado em 18 de novembro de 2011 